\title{
Skeletal radiology following hematopoietic stem cell transplantation in infantile osteopetrosis: an overlooked assessment tool
}

\section{Radiología esquelética posterior al trasplante de células madre hematopoyéticas en la osteopetrosis infantil: una herramienta de evaluación desestimada}

\author{
Tamer A. El-Sobky ${ }^{1 *}$ and Solaf M. Elsayed ${ }^{2}$ \\ ${ }^{1}$ Division of Pediatric Orthopaedics, Department of Orthopaedic Surgery; ${ }^{2}$ Division of Medical Genetics, Department of Pediatrics. Faculty of \\ Medicine, Ain Shams University, Cairo, Egypt
}

\section{Respected editor,}

We read with considerable interest the latest article published in your journal by Gaytán-Morales et al ${ }^{1}$. The genetic-skeletal diagnosis and management of a child with malignant infantile osteopetrosis were presented in a systematic and comprehensive manner ${ }^{1}$. The authors' reported outcome was satisfactory regarding the prevention of development of disease-related complications, the unremarkable course of allogeneic hematopoietic stem cell transplantation (HSCT), and the resolution of radiological skeletal abnormalities ${ }^{1}$. This study underscores the importance of both early diagnosis and multidisciplinary approach for management, which is especially relevant for rare diseases like malignant infantile osteopetrosis that usually has a fatal course in case of no or delayed treatment. HSCT has been successfully used to treat various genetic skeletal dysplasias as mucopolysaccharidosis, especially type $\mathrm{IH}$, and malignant infantile osteopetrosis ${ }^{2}$. However, treatment's success depends on several factors, age being the most important, and disease severity at the time of diagnosis, as well as the treatment ${ }^{2}$. The presence of other bone therapeutic modalities to treat genetic skeletal dysplasia further highlights the importance of early diagnosis of rare diseases ${ }^{2,3}$; the potential health economic burden of managing the disease-related complications of osteopetrosis as repeated infections and hospitalizations and occurrence of pathological fractures prompts early diagnosis and referral to a specialized center ${ }^{4}$. Noteworthy, the surgical management of pathological fractures in osteopetrosis is problematic concerning extended healing time and higher risk of infection regardless of osteopetrosis subtype ${ }^{4}$.

Unsurprisingly, most physicians tend to be unaware of the specific diagnostic features of rare diseases, including malignant infantile osteopetrosis. This unawareness can increase the incidence of misdiagnosis and the subsequent disease morbidity and mortality with delayed referral to a tertiary or disease specialized center. The fact that a considerable percentage of genetic skeletal dysplasias, including infantile forms of osteopetrosis, are not readily recognizable at birth compounds the diagnostic challenges. Additionally, patients with malignant infantile osteopetrosis may present with non-specific infections like 
community-acquired pneumonia, among others ${ }^{1}$. Despite the advances of genetic testing and imaging modalities, attention to basic clinical and plain radiographic correlations remains the cornerstone of diagnosis of genetic skeletal dysplasias ${ }^{5}$.

The reporting of rare cases ${ }^{1}$ in the literature is important because it expands the disease phenotype-genotype correlations, further elaborates on the clinical and pathological responsiveness to HSCT in the various subtypes of malignant infantile osteopetrosis, and thus provides information for decision making. Although the article demonstrated the positive radiographic skeletal response of the skull following HSCT, the axial and appendicular skeleton response was not reported. This point may be worthy to be investigated by the authors ${ }^{1}$ in an upcoming study, especially when their patient has been followed up for roughly three years. Most of the literature on HSCT use in malignant infantile osteopetrosis has focused on the amelioration of non-skeletal manifestations. Literature on radiologic responsiveness of skeletal abnormalities to HSCT in malignant infantile osteopetrosis included descriptive (categorical) assessment of plain radiographic assessment ${ }^{6,7}$. Two recent reports used analytical methods like bone morphological analysis by densitometry ${ }^{8}$ and nuclear magnetic resonance imaging (MRI) $)^{9}$ to quantify the skeletal responsiveness to HSCT. Generally, the short and intermediate-term outcomes were satisfactory ${ }^{8,9}$; herein, the skeletal radiologic responsiveness itself served as an outcome tool. Further studies are needed to show reliable correlations between skeletal radiologic responses to HSCT and the preoperative, genetic and transplant characteristics of the patient. For example, the studies by Shapiro et al..$^{8}$ and Gaytán-Morales et al. ${ }^{1}$ both included patients with osteopetrosis secondary to mutations in CLCN7. It would be interesting to know how these patients with the same underlying gene involvement correlate with respect to skeletal radiologic response following HSCT and how patients with the same mutation respond. In conclusion, the hematologic-non-skeletal responses-and skeletal responses to HSCT should be researched conjointly to draw a comprehensive and accurate picture of the treatment response.

\section{References}

1. Gaytán-Morales JF, Castorena-Villa I, Mendoza-Camargo FO, Cortés-Flores DC, Gómez-Domíguez YA, Montenegro-Chahar PD, et al. Hematopoietic stem cell transplantation in a patient with osteopetrosis and mutation in CLCN7: long-term follow-up. Bol Med Hosp Infant Mex. 2021;78:225-233. doi: 10.24875/BMHIM.20000105.

2. Otaify GA. Bone-specific therapeutic modalities for genetic skeletal diseases. Middle East J Med Genet. 2019;8:69-82.

3. Kılıç M, Dursun A, Coșkun T, Tokatı A, Özgül RK, Yücel-Yılmaz D, et al. Genotypic-phenotypic features and enzyme replacement therapy outcome in patients with mucopolysaccharidosis VI from Turkey. Am J Med Genet A. 2017;173:2954-67.

4. Yiğit Ş, Arslan H, Akar MS, Şahin MA. Mid-term outcomes of surgical treatment in fractures in patients with osteopetrosis. Bone Joint $\mathrm{J}$. 2020;102-B:1082-7.

5. El-Sobky TA, Shawky RM, Sakr HM, Elsayed SM, Elsayed NS, Ragheb SG, et al. A systematized approach to radiographic assessment of commonly seen genetic bone diseases in children: a pictorial review. J Musculoskelet Surg Res. 2017:1:25-32.

6. Hashemi Taheri AP, Radmard AR, Kooraki S, Behfar M, Pak N, Hamidieh $A A$, et al. Radiologic resolution of malignant infantile osteopetrosis skeletal changes following hematopoietic stem cell transplantation. Pediatr Blood Cancer. 2015;62:1645-9.

7. El-Sobky TA, El-Haddad A, Elsobky E, Elsayed SM, Sakr HM. Reversal of skeletal radiographic pathology in a case of malignant infantile osteopetrosis following hematopoietic stem cell transplantation. Egypt $\mathrm{J}$ Radiol Nucl Med. 2017;48:237-43.

8. Shapiro G, Fishleder J, Stepensky P, Simanovsky N, Goldman V, Lamdan R. Skeletal changes after hematopoietic stem cell transplantation in osteopetrosis. J Bone Miner Res. 2020;35:1645-51.

9. Maximova N, Zennaro F, Gregori M, Boz G, Zanon D, Mbalaviele G. Hematopoietic stem cell transplantation-induced bone remodeling in autosomal recessive osteopetrosis: interaction between skeleton and hematopoietic and sensory nervous systems. Bone. 2020;130:115144. 